\title{
Phaselis Kentinin Su Teminine İlişkin Gözlemler ve Dijital Epigrafi Çalışmaları
}

\author{
Observations Relating to the Water-Supply of Phaselis and Digitally Assisted \\ Epigraphic Studies
}

\section{Nihal TÜNER ÖNEN* Aykan AKÇAY ${ }^{* *}$}

$\ddot{O}_{z}$ : Burada sunulan makale Phaselis Antik Kenti ve Teritoryumu'nda 2012 yılından itibaren sürdürülen multidisipliner yüzey araştırmaları çerçevesinde kentin su teminine ilintili gözlemleri ve ele geçen epigrafik malzemelerin yeni teknolojiler ışığında çözümlenme sistematiğini tanıtmayı amaçlar. İlk olarak kentin aquaeductus'undan itibaren Tahtalı Dağ istikametinde Phaselis'e su sağlayan kaynaklar, su yapıları ve suyolları ele alınmıștır. Söz konusu verilerin koordinatlarının kentin topografik haritasına aktarılması sayesinde, söz konusu kaynaklar, su yapıları ve suyollarının harita üzerinde görünebilirliği sağlanarak kentin su temin ağına ilişkin bütüncül bir algı oluşturulmaya çalışılmıştır. Ardından Phaselis'ten ele geçen yazıtların daha iyi çözümlenmesi için yeni teknolojilerin kullanımına yönelik çalışmalar ele alınmıştır. Bu bağlamda yeni bir sayısal fotoğraflama metodu olan RTI ile fotogrametrik belgeleme sistemlerinin, taş malzeme üzerindeki epigrafik belgelerin görünür kılınmasına yaptığı katkı kentte bulunan yeni bir yazıt fragmanı üzerinde yapılan deneysel bir çalışma 1şı̆̆ında örneklemlendirilmiştir.

Anahtar sözcükler: Phaselis, suyolları, epigrafi, RTI, fotogrametri

Abstract: This article presents the observations made concerning the water supply to the city of Phaselis in antiquity and the deciphering of new epigraphic material with the aid of new technologies, within the framework of the multidisciplinary field work that has been conducted in the ancient city and within its territory since 2012. Firstly, through determining the water-sources, related constructions and distribution network conveying fresh water to Phaselis, from the city's aquaeductus to the water sources on Mount Tahtal, through field surveys and recording the coordinates of these finds on the city's topographical map. Secondly, an example of the benefits obtained through the new technologies employed to enable and facilitate the more accurate reading of the inscriptions found in Phaselis through the use of the new digital photography technique called $R T I$ and photogrammetry to improve the legibility of the inscriptions found on the lithic material, with an example provided by the studies of a new fragmentary inscription discovered in the city.

Keywords: Phaselis, water supply, epigraphy, RTI, photogrammetry

\footnotetext{
* Yrd. Doç. Dr., Akdeniz Üniversitesi, Edebiyat Fakültesi, Eskiçağ Dilleri ve Kültürleri Bölümü, Antalya. nihaltuner@akdeniz.edu.tr

** Arş. Gör., Akdeniz Üniversitesi, Akdeniz Uygarlıkları Araştırma Enstitüsü, Antalya, aykanakcay@akdeniz.edu.tr

Bu çalışma, Yrd. Doç. Dr. Nihal Tüner Önen tarafından "Phaselis Antik Kenti ve Teritoryumunun Epigrafik ve Hidrografik Araştırma Projesi" başlıklı ve 2013.01.0116.002 sayılı BAP Projesi kapsamında, gerçekleştirilen çalışmaların sonucunu içermektedir.
} 


\section{Su Teminine İlişkin Gözlemler}

Su yaşam için en temel gereksinimdir. Bu durum sadece içme suyuyla sınırlı değildir, fakat aynı zamanda hijyen ve gündelik ihtiyaçların karşılanması açısından da zaruridir. Bundan dolayı kentin uzun süreli su ihtiyacını karşılayacak rezervinin bulunması, yerleşimin kuruluş aşamasındaki en önemli faktörlerinden birini teşkil eder. Bununla birlikte her ne kadar kentin kuruluş aşamasında su ihtiyacını karşılamak güç olmasa da demografik yapının süreçbağımlı gelişim perspektifinde çeşitlenerek artması, kentin polis'ten metropolis'e geçiş aşamasında su yönetimi göz ardı edilemeyecek derecede önemli bir rol oynar. Phaselis kenti için de benzer bir sürecin yaşandığı varsayılabilir.

Arkaik-Klasik dönemlerde, daha çok akropolis üzerinde konuşlanmış olan kent sakinlerinin su ihtiyacı sarnıçlarda biriktirilen ve yakında bulunan kaynaklardan edinilen temiz su ile karşılanmış görünür. Bu sarnıçlar akropolis'nin deprem, erozyon ve dev dalgalar etc. gibi doğal afetler nedeniyle kırılmış olan falezlerinde izlenebilmektedir. Kepez kırığı doğal olarak sarnıçlar yüzünden zayıflayan yerde bulunur ve bundan dolayı da söz konusu su toplama/biriktirme alanlarının kalan kısımları bugün hala deniz tarafından kente bakıldığında falezlerde görülmektedir.

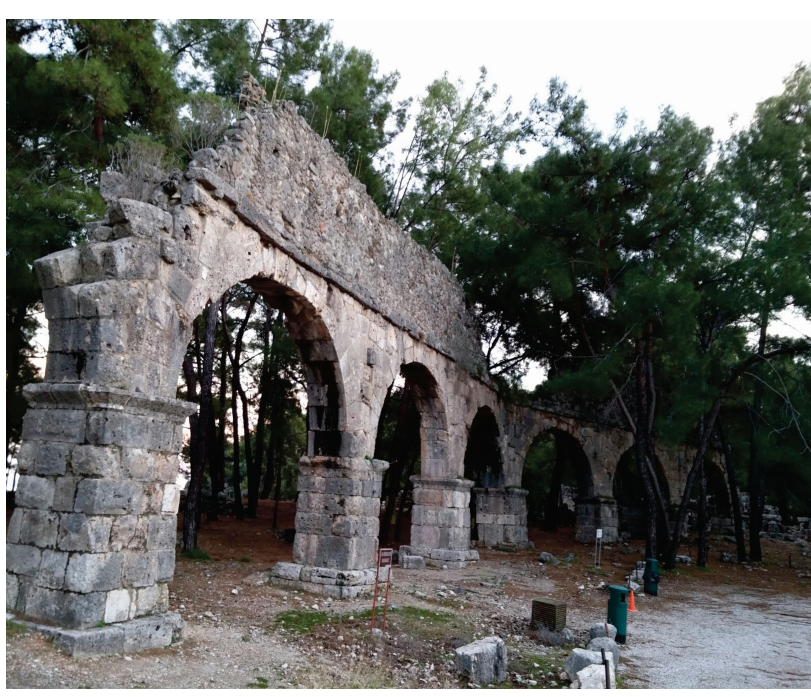

Fig. 1. Aquaeductus

Muhtemelen Hellenistik Dönem'den itibaren demografyanın gelişip çeşitlenmesine paralel şekilde kent sinırları kuzey ve batı yönde genişlemiş ve sarnıçlar su temini açısından yetersiz kalmaya başlamıştır. $\mathrm{Bu}$ sebeple yeni kaynaklar araştırılmış ve buralardan elde edilen suyun künklerle kente aktarılması sağlanmıştır. Phaselis kentinden başlayıp, Kuzey Yerleşim ve Tahtalı Dağ'ın doğu eteklerinde yürütülen araştırmalarda, kentin su ihtiyacının, Kuzey Yerleşim'in eteklerinde bulunan küçük su gözü dışında Tahtalı Dağ eteklerindeki birçok kaynaktan çağlayan sulardan karşılandığı tespit edilmiştir.

Kentin hidrografik yapısına ilişkin yürütülen çalı̧̧mamıza, tümdengelim çıkarımsama yöntemi ş̧ı̆̆ında deniz kıyısında kentin merkezinin su ihtiyacını karşılayan aquaeductus'tan başlanmıştır (Fig. 1). Kent limanı ile batı yerleşim ve göl arasında uzanan yapı kalıntıları aquaeductus'un günümüze kadar iyi bir şekilde korunmuş kısmını oluşturmaktadır. Kuzey yerleşim ve Tetragonal Agora'nın batısındaki tepelik arasındaki çukur alanı yüksek kemerlerle geçen söz konusu su yapısı sayesinde suyun kentin içine kadar taşındığ belgelenmiştir. Yak. 400 metreden fazla uzunluğa sahip Phaselis aquaeductus'u Roma suyolu şeklinde düzenlenmiş olup kabaca M.S. I-II. yüzyıllara tarihlendirilebilir.

Kuzey Liman'da, hemen sahil kenarında, denizin içinde görülen kalıntılar, aquaeductus'un kuzey yönünde devam ettiğini belgeler. Kuzey yerleşimin güneydoğu etekleri boyunca görünen ve geç dönem eklentileri ile farklı yapılar için duvar ve hatta sur olarak dahi kullanılmış olan su yapısı bu alanda hem denizin etkilerinden hem de taş-toprak kaymasından dolayı yer yer tahrip olmuştur (Fig. 2). 


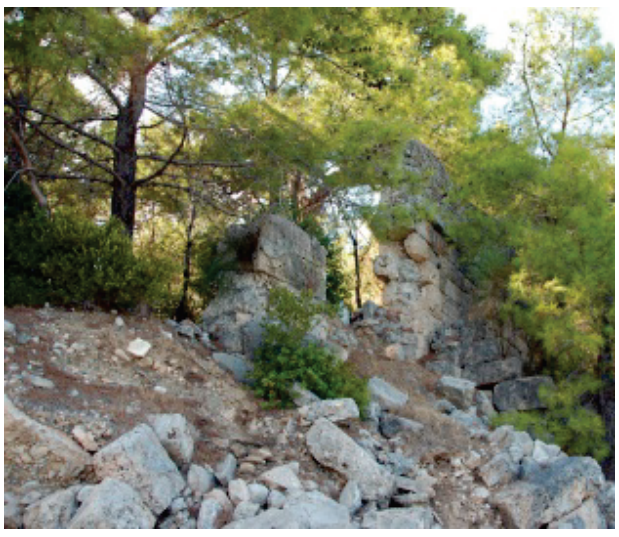

Fig. 2. Kuzey Yerleşim'in eteklerindeki Aquaeductus kalıntılar1
13 metre yükseklikte başlayan aquaeductus, kopuk olan son kısım üzerinde 7 metre kadar korunmuştur. Suyolunun inşasında kalker bloklar ve moloz taşlar kullanılmıştır. Kullanılan taş malzemenin büyük kısmı devşirmedir. Bu durum, yapının Geç Antikçağ' da geçirdiği tamirat ve bakıma işaret eder. Üst örtü plakası üzerinde seramik su künklerinin asıl taşıyıcısı olarak kırma taştan harçlı duvar örgüsü yükselir, bunun içinde devşirme malzeme ve kiremit parçaları da bulunur. Suyun aktarım yapısı, harçlı duvar yapısının üzerine üst üste açılmıș iki su künkünden oluşur (Aquaeductus'un için ayrıca bk.. Schäfer 1981, 42-48, lev. 7-9; krş. Ümit 1996, 19-22). Bu alanda aquaeductus duvarının $1 \mathrm{~m}$. doğusunda sahile bakan yamaçta da harçlı künk parçaları tespit edilmiştir (Fig. 3).

Aquaeductus'un yamaçta sonlandiğı kısımdan itibaren, Kuzey Yerleşim olarak adlandırılan Hellenistik Dönem'e tarihlenebilecek mimari kalıntılar ve güçlü bir tahkimat yapısı gösteren iskan alanına doğru devam eden su aktarım sistemi, arazide tespit edilen su künklerine ait seramik kalıntılar sayesinde takip edilebilmektedir (Fig. 4). Kuzey Yerleşim'in tüm doğu-kuzeydoğu etekleri boyunca sürdürülen araştırmalarda, bu alanda suyun sadece bir künk sistemiyle değil, birkaç farklı istikamette devam eden ve künklerle oluşturulan su dağıtım sistemiyle aquaeductus'a iletildiği tespit edilmiştir. Bu durum, aquaeductus'a sadece Tahtalı Dağ'dan değil, aynı zamanda Kuzey Yerleşim'in kuzeydoğu ve güneydoğu eteklerindeki mağaralardan ve Alacasu istikametinde bulunan su rezervuarı gibi alanlardan da su temin edildiğini göstermektedir.

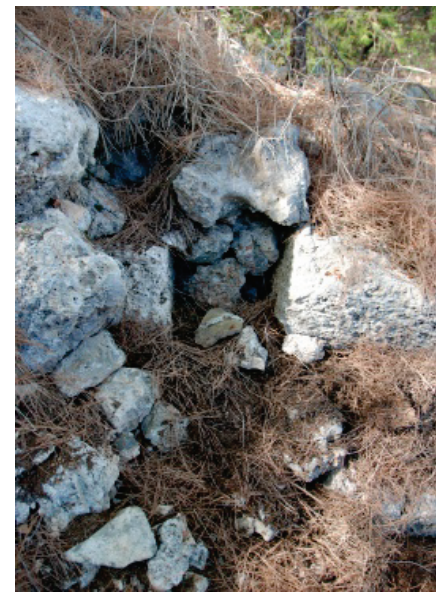

Fig. 3. Harçlı künk parçaları

Hellenistik akropolis'in ve Kuzey Yerleşim'in yer aldığı kayalık plato üzerinde doğukuzeydoğu istikametinde ilerlenirse nispeten derin ve dik olarak plato kütlesi içene doğru yarılmış kısa bir vadinin uzandığı görülür. Burada plato dar sahil çıkıntısına doğru sert bir

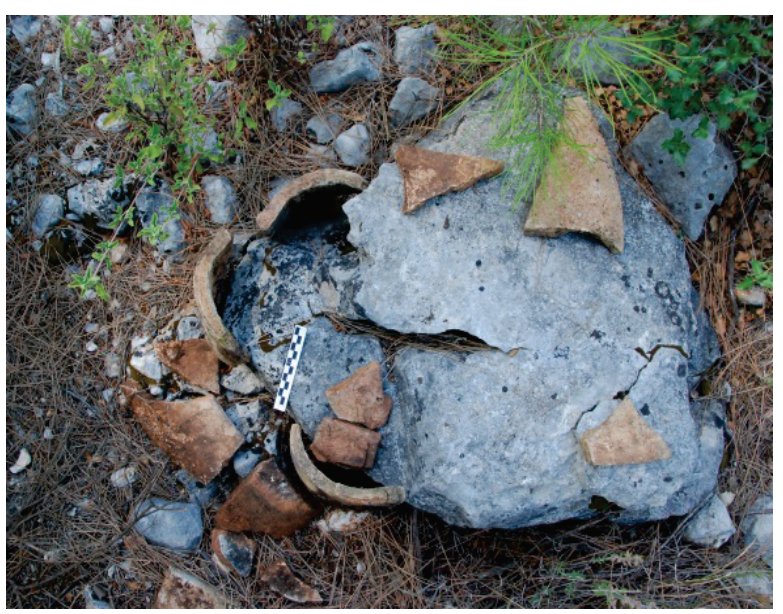

Fig. 4. Yüzeyde Görülen Künk Parçaları şekilde inerek; buradan itibaren ise kademeli şekilde alçalır.

Yukarıda söz konusu edilmiş rezervuar da bu platonun yaklaşık 40 metre kadar aşağısında yer alır. Yapının ağzı $2.65 \mathrm{~m}$. çapında, derinliği ise $17.67 \mathrm{~m}$. derinliğindedir (Fig. 5). H. Schläger ve J. Schäfer'in 1969-1970 yılı araştırmaları sırasında yapının derinliği $25.7 \mathrm{~m}$. olarak ölçülmüştür (Schäfer 1981, 48 vd.). Fakat günümüzde yapının altının çökme, sedimantasyon ve yukarıdan atılan çöplerle dolduğu tespit edilmiştir. 


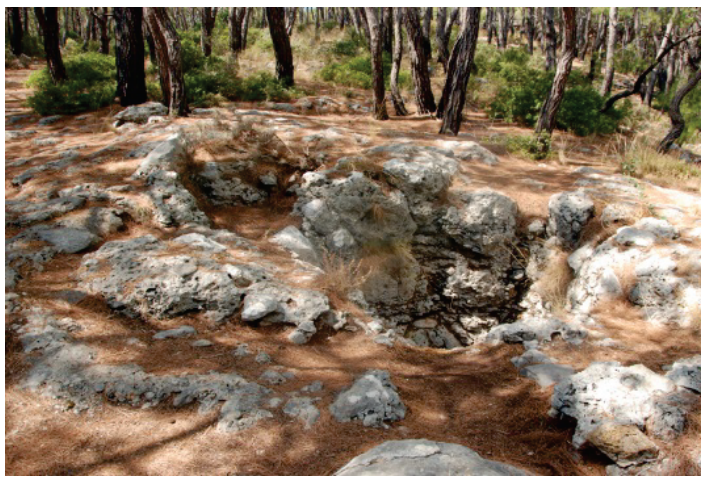

Fig. 5. Rezervuar yapısının ağız kısmı

Rezervuar kuzeybat1-güneydoğu istikametinde olup hafifçe batıya doğru kıvrılarak dere vadisi doğrultusunda bir tünel şeklinde yaklaşık $40 \mathrm{~m}$. boyunca uzanmaktadır. Yer yer ana kayadaki açıklıklar düzeltilerek şekillendirilmiştir. İki ana kayanın oluşturduğu yarık $129 \mathrm{~cm}$. ile 180 $\mathrm{cm}$. arasında değişmektedir. Kuzeyindeki vadiden (şu an sadece kışın) akmakta olan dereye doğru yönelen rezervuarın kuzey tarafında obruk benzeri bir alan mevcuttur. Burada suyun sızmasıyla oluşmuş olmakla birlikte günümüzde büyük ölçüde zarar görmüş sarkıt ve dikit örnekleri göze çarpmaktadır. Yapıya birbirine paralel şekilde inen, kuzey-güney istikametinde insan eliyle kayaya oyulmuş ve düzlenmiş yaklaşı $60 \mathrm{~cm}$. genişliğe sahip 3 sıra kaya merdiveni mevcuttur (Fig. 6). Bunların üzerinden güney istikametinde yarığın (rezervuarın) temelinden yukarıya çıkılabilmektedir. Önceki kaya zemini bugün, boyutu tespit edilemeyen döküntüler ve dolgular altında kalmıştır.

Bir bölümü doğal, bir bölümü ise insan eliyle şekillendirilmiş yarığın üstü kemerlerle örtülmüş olsa gerektir. Kemerlerin bir k1smı halen in-situ olarak korunmuştur. Bu üst örtü güney uçta daha önce de sözü edildiği üzere yuvarlak bir boşluk aracıllğıyla kuyu ağzı tarzında delinmiştir. Yapının hemen kuzeyinde uzanan bir vadi yatağından dere akmaktadır. Güneyinde ise nekropolis'e ait khamasorion'lar ve lahitlerden oluşan yaklaşık 100 m'lik bir teras mevcuttur. Rezervuarı çevreleyen arazinin yüzeyinde, zarar görmemiş orman tabanı içinde herhangi bir yapı işçiliği kalıntısı tespit edilememiş̧ir. Söz konusu teras 100 m'nin sonunda falez şeklinde Phaselis'in kuzey limanında bir koyla sonlanmaktadır. Buradaki alan kentin su depolama ve dağıtma sisteminin bir parçası olsa gerektir. Zira Schläger ve Schäfer'ın da bahsettiği gibi, burada bugün devam eden bir tünelin eklentisi olabilecek suyoluna ait izler mevcuttur. Yapı, vadiden kaynaklanan suyun toplanması için de kullanılmış olabilir.

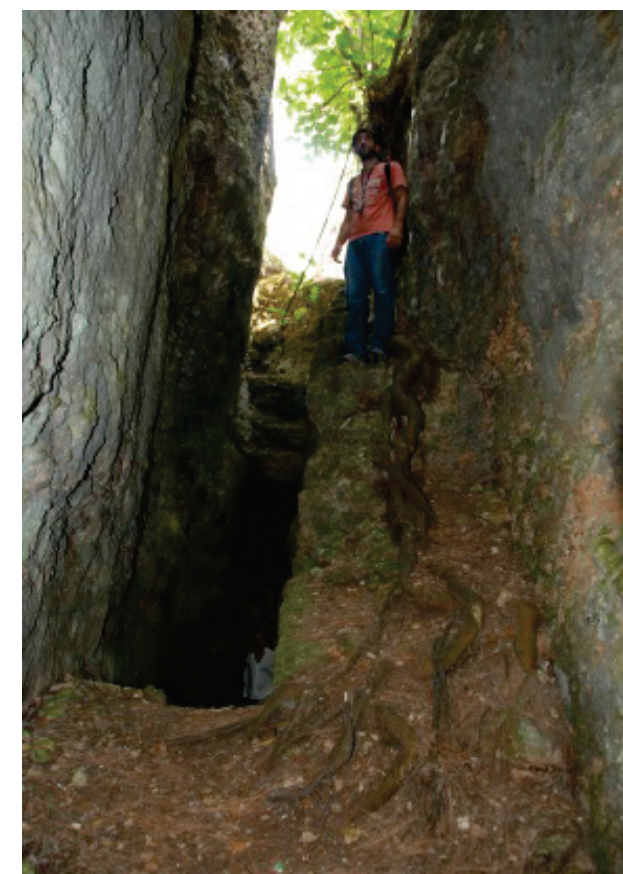

Fig. 6. Rezervuar yapısı kaya merdivenleri

Kuzey Yerleşim'den Tahtalı Dağ istikametinde takip edilebilen su aktarım kalıntıları, modern Antalya-Kumluca karayolu sebebiyle kesintiye uğrasa da, yolun Tahtalı Dağ yönünde tekrardan görülebilmektedir. Teleferik gişesi civarında Telefon Gediği mevkiinde büyük ölçüde sağlam ve kolaylıkla izlenebilir konumda olan suyolunun bazı bölümleri teleferik için yapılan yol çalışmaları sırasında tahrip edildiğinden bu bölümlerde herhangi bir kalıntı izi maalesef günümüze ulaşmamıştır. 
Söz konusu suyolunun her iki tarafi kaba polygonal kireçtaşından yapılmıştır ve su muhtemelen orta kısma döşenen su künkleri aracıllı̆ıyla güvenli ve temiz bir şekilde aktarılmıştır (Fig. 8). Suyolu boyunca uzanan yapının üzerinde ve çevresinde tespit edilen, künklerin kavisiyle uyumlu dış yüzeyleri sarı, iç yüzeyleri kırmızı kalın seramik parçaları da bu olasılığ güçlendirmektedir.

Oldukça net bir şekilde izlendiği üzere söz konusu suyolu, Telefon Gediği alanından Yerleştir Sırtı'nın hemen kuzeyinde bulunan vadiye kadar düz bir hat olarak kuzeydoğu-güneybatı istikametinde uzanmaktadır. Söz konusu vadinin Kale Mevkii'ne doğru yükselen kısmında çiftlik yerleşimlerine ait olabilecek yapı kalıntıları, mezar yapıları ve teraslar içeren küçük bir yerleşim alanı tespit edilmiştir (Fig. 9). Phaselis istikametine doğu ilerleyen teraslar şeklinde planlanmış olan yerleşimin Hellenistik ve Roma dönemlerinden Geç Antikçağ'a kadar kesintisiz olarak iskan edildiği saptanmıştır. Birden fazla odaya sahip, iyi derecede korunmuş yapılar oldukça kompakt bir plan çerçevesinde inşa edilmişlerdir. Yapılar arasında dar yollar ve sokaklar izlenebilmektedir. Alanda tespit edilen işliğin de gösterdiği üzere köy halkının geçimini tarım ve hayvancılık üzerinden sağladığı söylenebilir. Yüzeyde künk parçaları ve muhtemelen künklerin üzerini kapatan düz plakalar tespit edilmiştir. Söz konusu künk parçaları köyün hemen eteklerinde bulduğumuz suyolu ile aynı istikamette yer almaktadır. $\mathrm{Bu}$ durum, doğal olarak suyolundan köye doğru da bir su aktarımının yapıldığına işaret etmektedir.

Kome'nin (köy) kuzeyinden geçen teleferik yolunun kuzey tarafindaki tepelik alanda ise bir kule yapısı ve bu kuleyle bağlantılı yapı kalıntıları bulunmaktadır (Fig. 10). $6.8 \mathrm{~m} \times 6.5 \mathrm{~m}$ kare planlı (içten içe) olan kule yapısı, $1.4 \mathrm{~m}$. kalınlığında iki sıra bosajlı dikdörtgen, düzgün kesilmiş bloklardan örülmüştür. Duvarlar büyük oranda korunmuş olup mevcut duvar yüksekliği 4.7 m'dir. Yapının kapısı güneye bakmaktadır. Kapının yanında bir pencere görülmekte olup batıya bakar vaziyettedir. Bloklar birbirine geçecek şekilde yuvalara

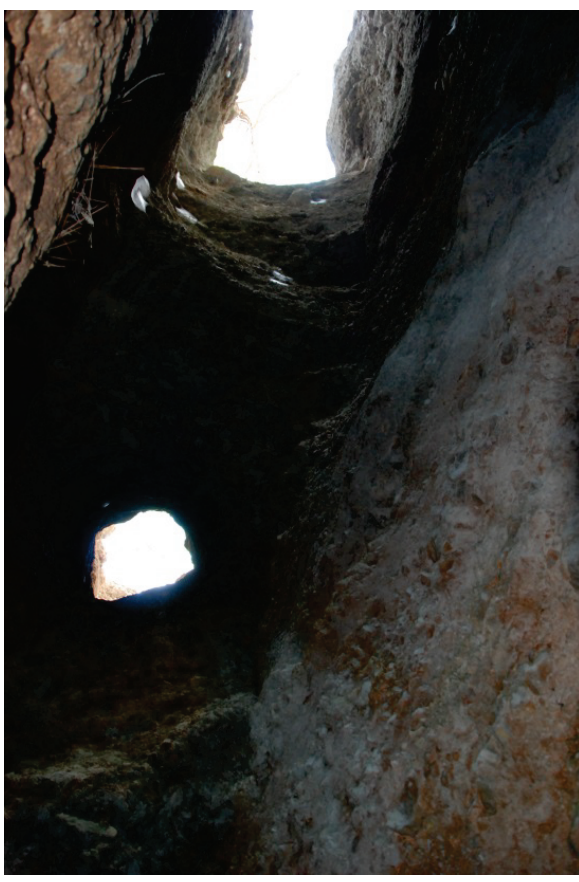

Fig. 7. Rezervuarın içinden yukarıya bakış

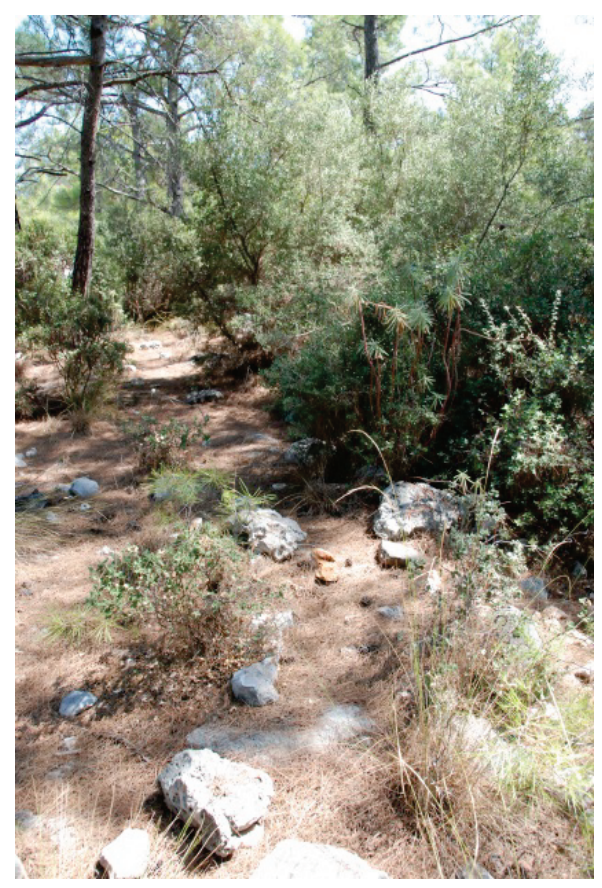

Fig. 8. Suyolu kalıntısı sahiptir. Yapı ana kaya üzerine oturmaktadır. Kulenin çevresinde 70 ile 100 m'lik alanda yap1 ve istinat duvarı kalıntıları mevcuttur. Yapının ard alanı Akboyun mevkiine kadar tarım amaçlı teraslanmış olup civarda birçok çiftlik evi tespit edilmiştir. 


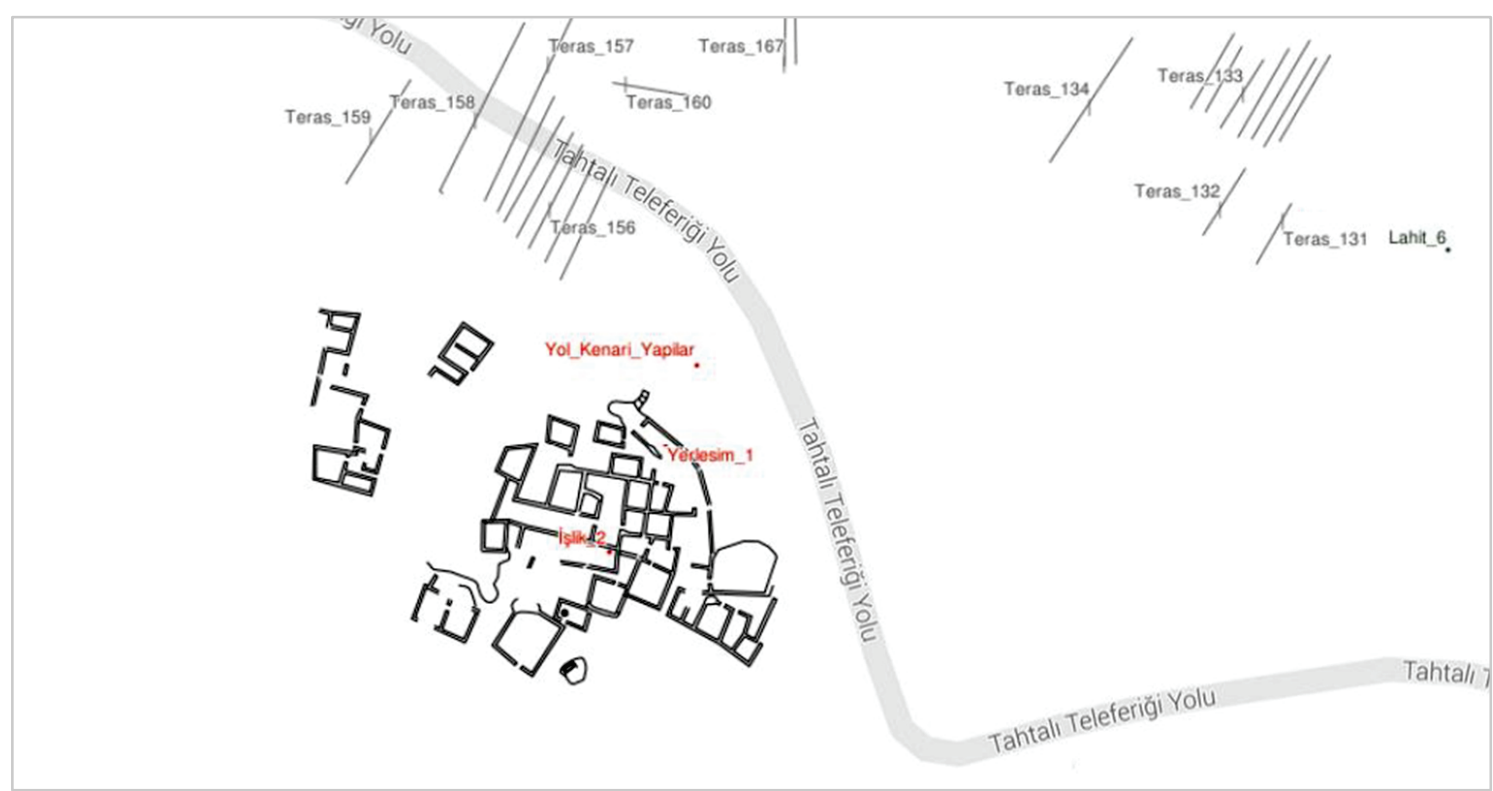

Fig. 9. Yerleştir Sırtı’nın kuzeyinde yer alan küçük yerleşim (Plan: Beydağları Yüzey Araştırmaları Arşivi).

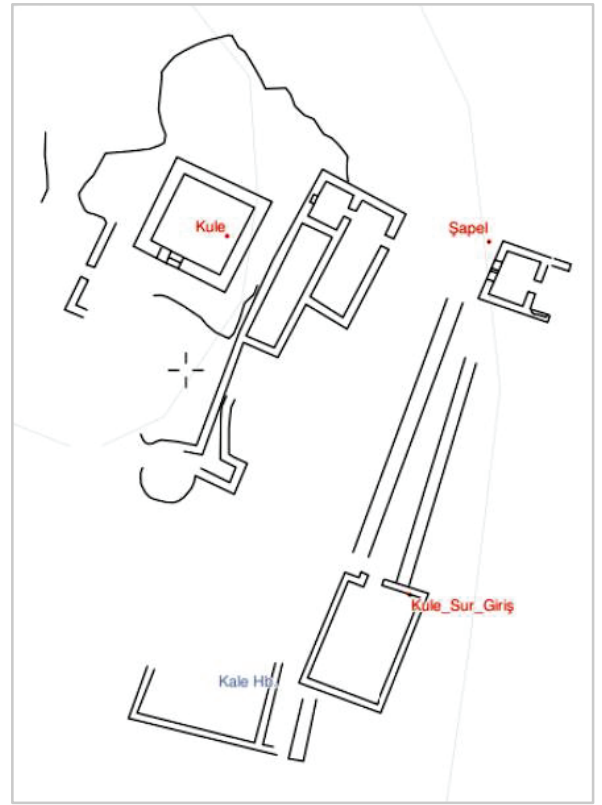

Fig. 10. Hellenistik Kule ve etrafindaki yapı kalıntıları (Plan: Beydağları Yüzey Araştırmaları Arşivi). Suyolunun üzerindeki polygonal kireçtaşı bloklar yaklaşı $1.3 \mathrm{~m}$ genişliğe sahip olup oyulmuştur ve içinden kanal geçmektedir. Kanalın oyuk kısmı yak. $40 \mathrm{~cm}$. genişliğe, $15-25 \mathrm{~cm}$. arasında değişen derinliğe sahiptir ve yer yer ana kayayı izlemektedir (Fig. 13). Gerek kanalın üzerinde gerekse her iki yakasında çok miktarda künk parçalarına rastlanmaktadır. Su kanalı hemen kuzeydoğusundaki vadiden akmakta olan dereye doğru uzanmaktadır. Çok yoğun bitki örtüsüne rağmen kanal ve üzerinde konuşlandırıldığı duvar her iki istikamette yaklaşık 100 'er m. boyunca açık bir şekilde takip edilebilmektedir. 


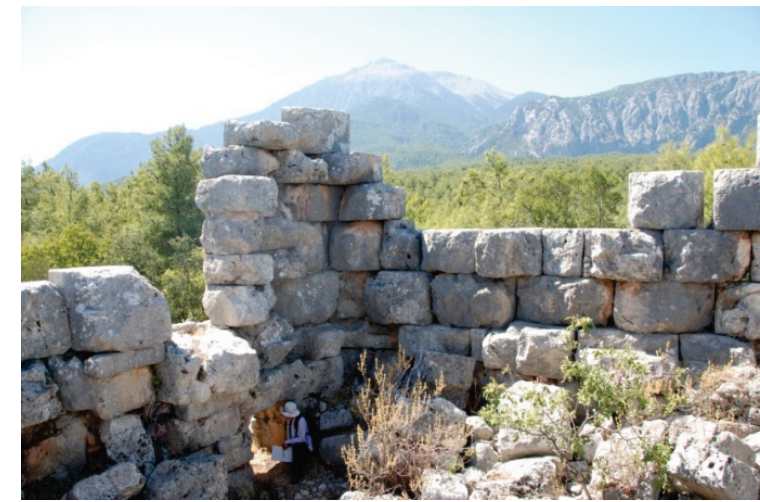

Fig. 11. Hellenistik Kule

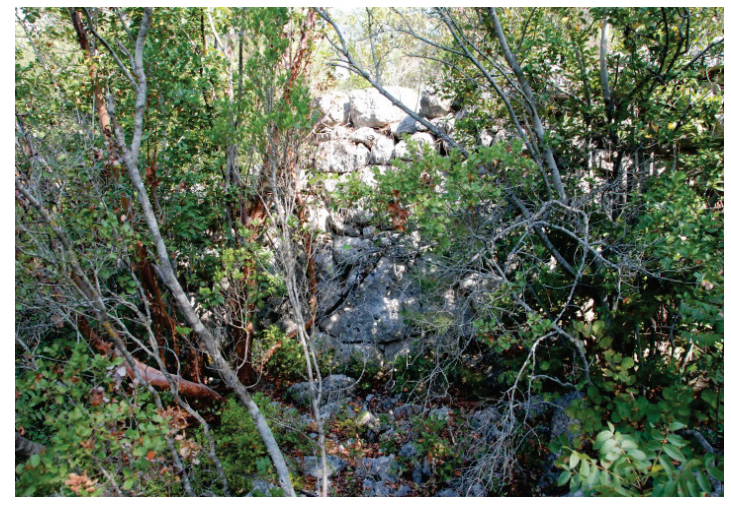

Fig. 12. Kome'nin 150 metre kadar güney doğusunda tespit edilen suyolu

Büyük, şekilsiz, kaba kireçtaşlarından yapılma duvar monumental bir görünüm sergilemektedir. Suyolunun yaklaşık 6-7 m. güneybatısından aquaeductus'a paralel, kyklopik derecede büyük bloklardan inşa edilmiş bir istinat duvarı uzanmaktadır. Kimi kısımlada 3-3.5 m. yüksekliğe ulaşan duvarın blokları yaklaşık $1.5 \mathrm{~m}$. genişliğe $1 \mathrm{~m}$. yüksekliğe sahiptir. İstinat duvarıyla suyolu arasındaki kısmın eğimi son derece düşüktür. Büyük bir ihtimalle bu alan servis yolu olarak kullanılmış olmalıdır.

Yerleştir Sırtı'ndan itibaren Gökgür Alanı'na doğru devam ettirilen araştırmalarımız sırasında suyolunun yine polygonal taşlardan yer yer 2 m'yi aşan yüksekliğe sahip bir şekilde devam ettiği tespit edilmiştir (Fig. 14). Yol, yaklaşık $1.5 \mathrm{~m}$. genişliğe, $55 \mathrm{~cm}$. yüksekliğe ve 50 $\mathrm{cm}$. ene sahip kireç taşlarından inşa edilmiştir. En üst sıra taş tabakası üzerinde kimi bölümleri ana kayaya oyulmuş yaklaşık 35-40 cm. genişliğe ve 15-20 cm. yüksekliğe sahip bir su kanalı açılmıştır.

Her iki istikamete doğru yaklaşı 70 m boyunca takip eden kanalın hemen çevresinde kalın seramik parçaları ele geçmiştir. Suyolunun üzerinin bu parçalarla kapatılıp kapatılmadığ ş̧u an için tespit edilememiştir.

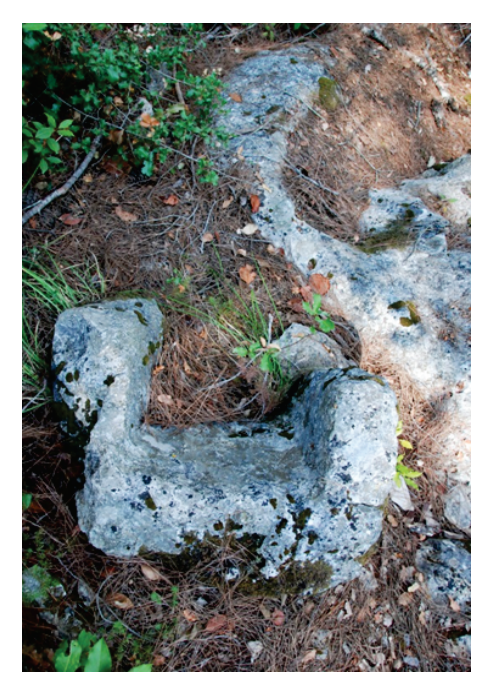

Fig. 13. Künklerin yerleştirildiği oyuklar

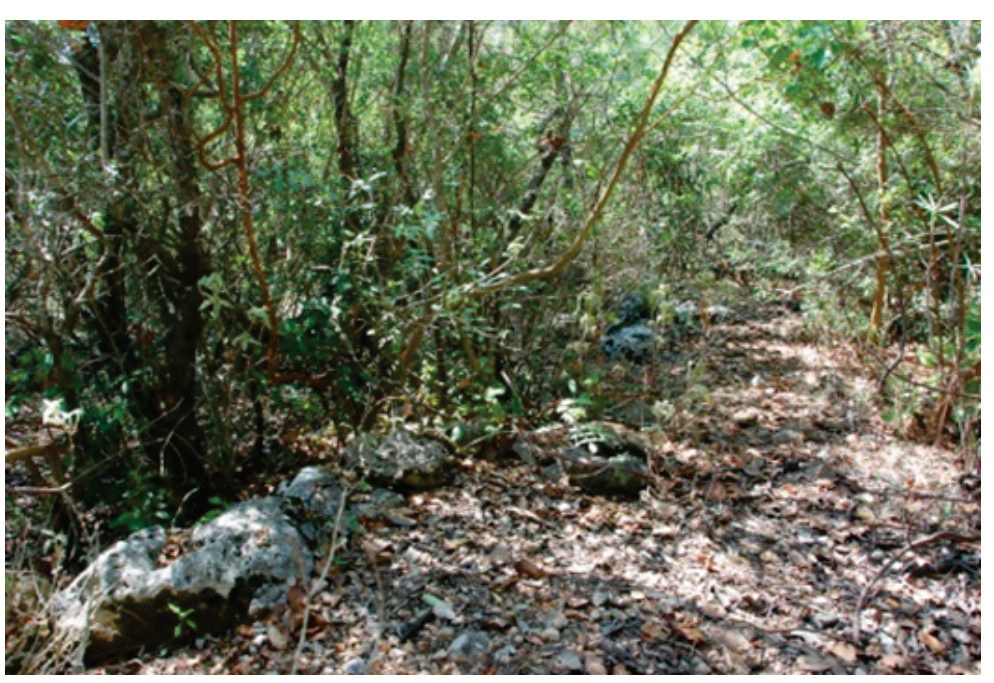

Fig. 14. Gökgür Mevkiinde Tespit edilen suyolu 


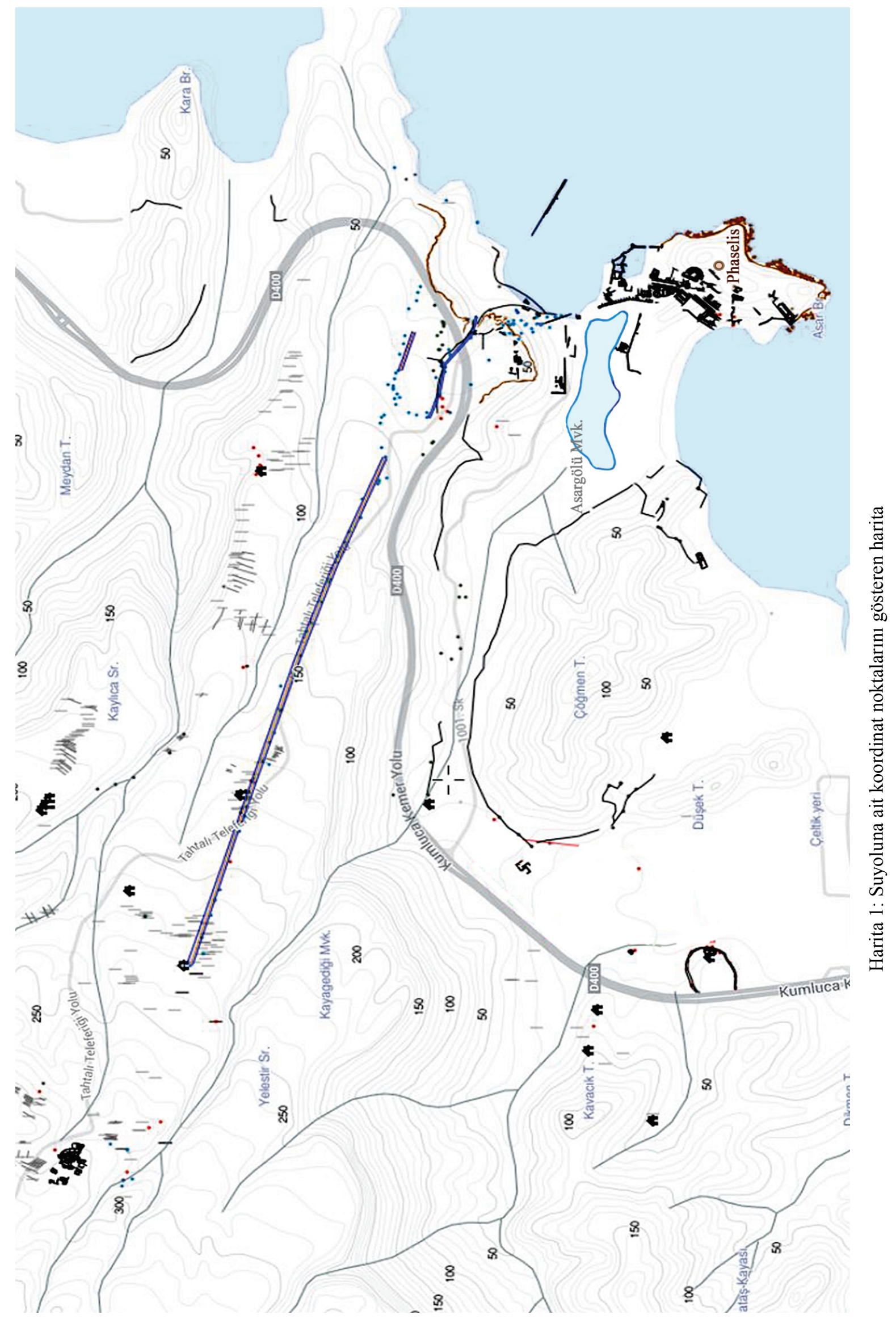




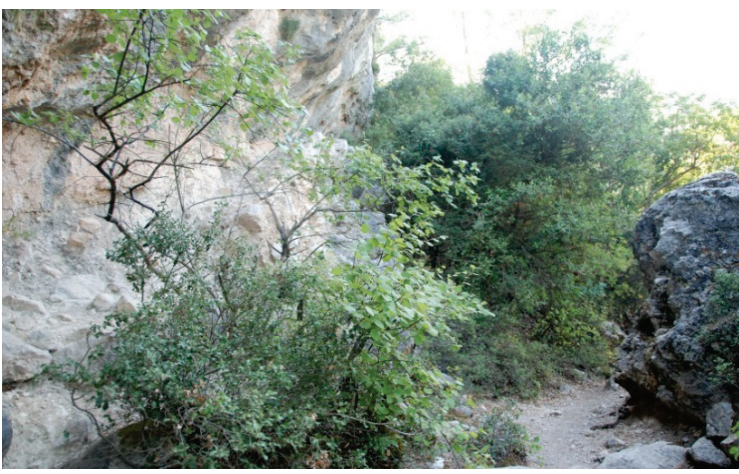

Fig. 15. Tamtır Alanı-Akboyun mevkileri arasında tespit edilen suyolu
Kentin su kaynaklarını tespit etmek üzere Tahtalı Dağı'na çıkan teleferik istasyonunun konuşlandırıldığı Akboyun'dan Sizgılı Kaya ve Tamtır Alanı'na doğru araştırma devam ettirilmiştir. Yer yer $2 \mathrm{~m}$. genişliğe varan ve istinat duvarlarıyla desteklenmiş antik güzergah Tamtır Alanı'na kadar takip edilmiş, gps noktaları alınarak fotoğrafları çekilmiştir (bk. Harita 1). Söz konusu güzergahın kimi yerde üzerinden kimi yerde de hemen batısındaki kayaya oyulmuş, Phaselis'e su taşıyan hatta ilişkin veriler toplanmıştır (Fig. 15).

$\mathrm{Bu}$ su hattının künklerle döşenmiş olup bazen antik yolun altından bazen de $120 \mathrm{~cm}$ 'ye varan istinat duvarlarıyla desteklenerek doğal kayanın ve tepenin eteğinden ilerlediği tespit edilmiştir. Tamtır Alanı'nda kuzeybatı istikametinde suyun hemen kenarından vadi boyunca yak. $70 \mathrm{~m}$. kireçtaşından yapılma bir duvar ilerlemektedir. Ayrıca yörede iskana ait arkeolojik kalıntılar mevcuttur. Phaselis suyolunun başlangıcı olması muhtemel olan bu alanda bugün hala kayadan bir kaynak çıktığı tespit edilmiştir (krş. Ümit 1996, 13; Fig. 16).

Arazide yürütülen çalışmalar sonucunda, Phaselis'in Tahtalı Dağ'da yer alan kaynaklardan sağlanan su teminine ilişkin kalıntılar, kente ulaşan suyolu güzergahının ana hatlarını belirleyecek oranda haritaya işlenmiştir (bk.. Harita 1). Buna göre Tahtalı Dağ'ın doğu eteklerinde, Tamtır Alanı'nın yaklaşık 200 m kadar üstünde, Mağara Deliği yakınındaki dar kayalıklardan çıkan kaynak, Tamtır Alanı'ndan itibaren künklerle Sizgılı Kaya, Ak Boyun, Haruplu Boyun ve Yerleştir Sırtı mevkilerine iletilmektedir. Akboyun Mevkii'nde suyolu izlenimi veren yığma yapı sırası, suyun bu alanda açık kanal olarak devam ettiğine işaret etmektedir (bu yönde yürütülen daha önceki çalışmalar için bk. Ümit 1996, 13-15; Tüner Önen 2008, 79-82). Bu alandan güneydoğu istikametine doğru inildikçe su kanalının bir kanadını oluşturduğu görülen sıralı kaya parçaları tespit edilmektedir. Söz konusu suyolu hattını takip ederek Kale Mevkii'nin güney batısında tespit edilen ve yer yer $3.5 \mathrm{~m}$. yüksekliğe kadar ulaşan, polygonal taşlardan örme suyoluna ulaşılmaktadır. Burada saptanan suyolu yaklaşık $70 \mathrm{~m}$. kadar Phaselis yönünde doğuya doğru takip edilebilmektedir. Harçsız, kuru örme şeklinde inşa edilen suyolunun en üst sırasının yaklaşık 15-25 m. derinlikte oyuklara sahip bloklardan oluşması, bu alanda da suyun açık kanal içinden aktarıldığına işaret etmektedir. Buradaki açık kanalların

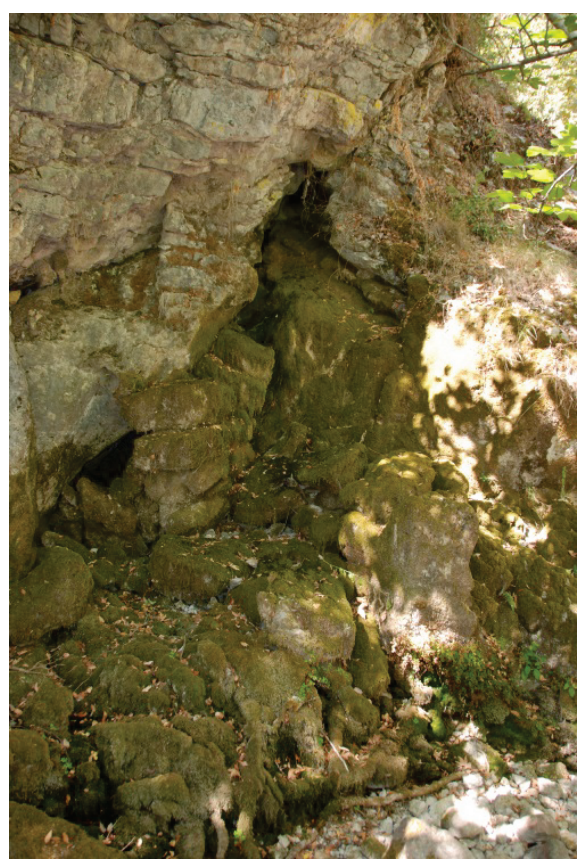

Fig. 16. Tamtır Alanı Kaynak üstü muhtemelen yine seramikten yapılma kapaklarla örtülüyor olmalıdır. Yerleştir Sırtından itibaren Telefon Gediği Alanı'na ve Kuzey Yerleşim'in Antalya-Kumluca Yolu tarafindan kesintiye uğradığı noktaya kadar tespit edilen künk kalıntıları düz bir hat oluşturmaktadır. Bu hat boyunca, her iki tarafı kalın şekilsiz kireçtaşlarıyla, ortası moloz taşlarla örülmüş, duvar 
yapısının uzandığı görülmektedir. Birçok alanda doğal-zamana özgü yıkımlarla tahrip olmuş söz konusu duvarın üzerinde ve çevresinde çok sayıda künk parçası bulunmaktadır. Hep aynı tarzda kaba kilden yapılma künk parçaları suyolu boyunca modern teleferik yoluna kadar teraslara paralel olarak kesintisiz takip edilebilmektedir. Söz konusu suyolu topografyaya uygun olmakla birlikte çoğunlukla aynı doğrultudaki terasları (kuzey-güney) birbirinden ayırmaktadır. Antalya - Kumluca Yolu'nun sebep olduğu kesintiden sonra Kuzey Yerleşimin kuzeybatısından itibaren kentin Kuzey Limanı'na doğru yönelmiş çok sayıda su aktarım kalıntısı tespit edilmiştir. Bu alanda, kaynaklardan toplanan sular künklerle aquaeductus yapısına iletilmiştir. Bu noktadan itibaren ise aquaeductus tarafından iletilen su kentin ihtiyacına göre su künkleri ile kent içi dağıtımına yönlendirilmiştir.

\section{Dijital Epigrafi Çalışmaları}

Epigrafi çalışmalarında karşılaşılan en büyük problemlerden biri yazıt taşıyıcısının korunma durumudur. Uzun yıllar açık hava koşullarına maruz kalan yazıtların yüzeyinde görülen aşınma ve kırılmalar metnin çözümlenmesini zorlaştırmaktadır. Bu durum yazıtların çözüm sürecinde hatalara neden olmakta hatta deşifre edilmesini imkansız hale getirmektedir. Kültürel miras araştırmalarında özellikle yurt dışında kullanılan yeni teknolojik uygulamalar sayesinde bu sorunların çözümüne yönelik bazı ilerlemeler kaydedilmiştir.

$\mathrm{Bu}$ yöntemlerden bir tanesi son yıllarda geliştirilen ve genellikle endüstri alanında kullanılan 3 Boyutlu Lazer Tarama (3D Laser Scanning) teknolojisidir. Bu uygulama, firlattığ lazernoktalar sayesinde herhangi bir nesnenin 3 boyutlu modelini hızlı bir şekilde oluşturmayı mümkün kılmaktadır. Fakat söz konusu teknolojiyi kullanmak oldukça maliyetlidir. Bu sebeple, 3B Lazer Tarama metodu ile aynı sonuca odaklı ve maliyet açısından daha uygun bir yöntem olan fotogrametri tekniği daha çok tercih edilir bir uygulama olarak görülmeye başlanmıştır. Diğer bir teknolojik yöntem ise Türkçe'ye Yansıtma Dönüşümlü Görüntüleme olarak çevrilebilecek Reflectance Transformation Imaging (RTI) interaktif aydınlatma ile fotoğraflama sistemidir.

Bu çalışmada Phaselis Antik Kenti ve Teritoryumunda süregelen disiplinlerarası yüzey araştırmaları kapsamında yürütülen epigrafi çalışmalarında, Fotogrametri ve RTI metodolojileri deneyimlenerek söz konusu teknolojilerin epigrafi bilimine sunduğu yenilikler bir yazıt fragmanı üzerinde elde edilen bulgular ışığında incelenmektedir.

\section{Yansıtma Dönüşümlü Görüntüleme (RTI)}

Reflectance Transformation Imaging (RTI) bir nesnenin yüzey formunu, dokusunu ve renk değerlerini yakalayarak nesnenin üzerinde ışığın interaktif olarak farklı açılardan uygulanmasına olanak veren, sayısal bir fotoğraflama metodudur. Bu metot ilk olarak Hewlett Packard (HP Labs) araştırmacıları Tom Malzbender ve Dan Gelb tarafindan Polinom Doku Kaplama (PTM) tekniği adı altında 2001 yılında gerçekleştirilen denemelerle kullanılmaya başlanmıştır (Malzbender, Gelb, \& Wolters, 2001, 519-528). 2006 y1lında Cultural Heritage Imaging (CHI) ekibi ve T. Malzbender bu tekniği kültürel miras araştırmalarında analiz ve belgeleme sistemlerinde uygulamak üzere Reflectance Transformation Imaging (RTI) adı altında duyurmuşlardır (Mudge, Malzbender, Schroer \& Lum, 2006).

$R T I$ görüntüleri, sabitlenmiş bir fotoğraf makinesinden çekilen bir dizi fotoğraftan elde edilen verilerden oluşmaktadır. Her bir fotoğraf karesinde sabit durumdaki materyal üzerine farklı açılardan uygulanan 1şık obje üzerinde yansıma ve gölgeler meydana getirmektedir. Elde edilen bu veriler sayısallaştırılarak sentezlenmekte, objenin matematiksel yüzey modeli oluşturularak $R T I$ yazılımı üzerinde kullanıcılar tarafından 1şığın istenildiği açıdan yansıtılmasına 
olanak sağlanmaktadır. Bu şekilde obje yüzeyinin çok yönlü analizi yapılabilmekte ve materyal kültür kalıntısına ait karanlıkta kalan birçok nokta aydınlatılabilmektedir.

$R T I$ dosyalarının incelendiğ $\mathrm{i}$ programda (RTI Viewer, Fig. 17), görüntüsü kaydedilen materyal üzerindeki yüzey detaylarının geliştirilmiş seçeneklerle görüntülenmesiyle, çeşitli etkenlerden dolayı (zaman, aşınma, zararlı likenler, vandalizm) yüzeyi zayıfla-
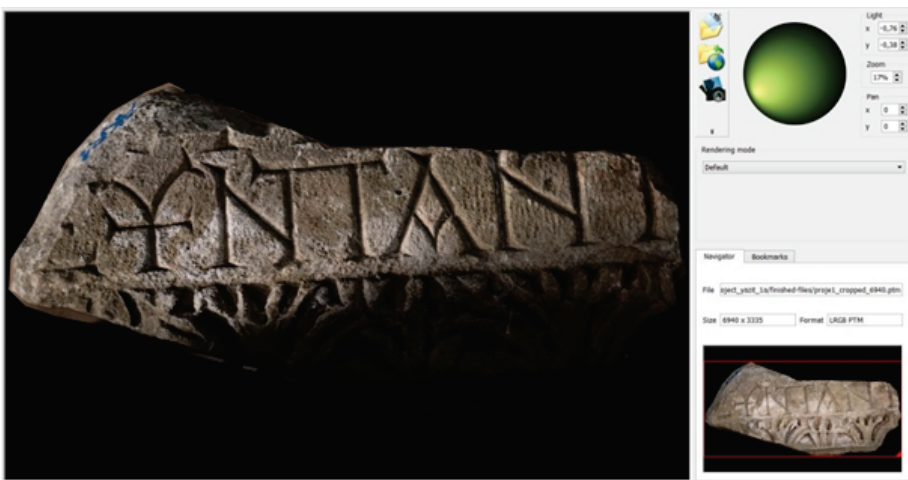

Fig 17. RTI-Viewer programından bir ekran görüntüsü: Ariștrav parçası üzerine saat sekiz yönünde sanal ışık uygulandığında insizasyonlar gölgeye düşmekte ve deşife edilmesini kolaylaştırmaktadır. yan/belirsizleşen materyal kültür kalıntılarının çıplak gözle algılanamayan yüzey detaylarının görünür kılınması ve analiz edilmesi mümkün k1lınmaktadır.

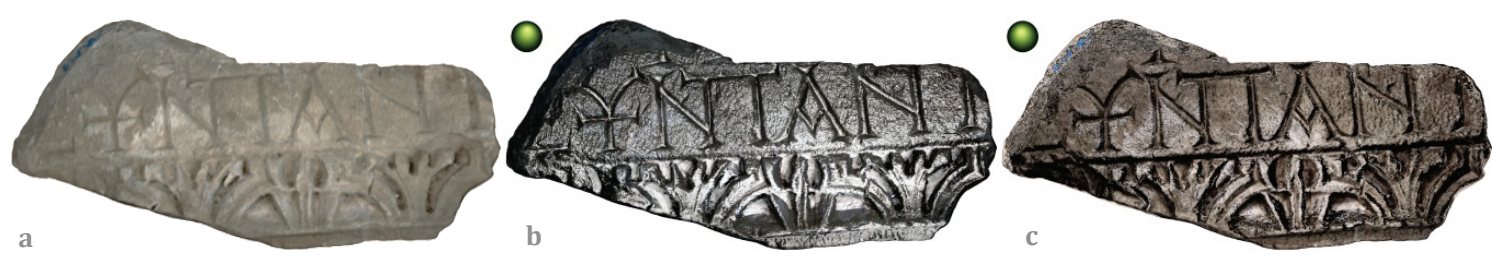

Fig. 18. (a) Yazıtın normal fotoğrafı (b) RTI Viewer specular-enhancement modu (c) diffuse-gain modu.

RTI Viewer programında, görüntü işleme seçeneklerinden specular-enhancement ve diffuse-gain uygulandığında eserin üzerindeki mimari bezekler ve yazıtın harf karakterleri son derece belirgin hale gelmektedir (Fig. 18).

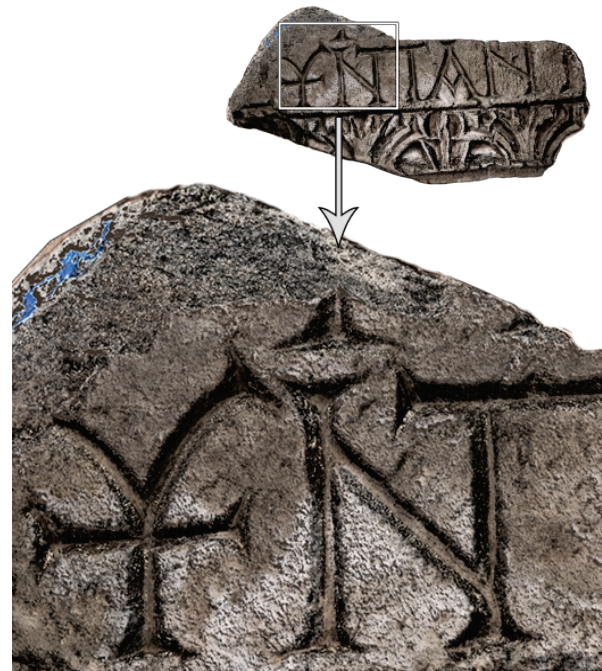

Fig 19. Diffuse-gain modunda detay görünümü.
Figür 19 incelendiğinde metodun yüksek detaylarda, materyalin en ince ayrıntısına kadar analiz imkanı sunduğu açık bir şekilde görülebilmektedir. Arşitrav parçasının kırık üst tarafında çıplak gözle bakıldığında neredeyse belli olmayan harf kalıntıları RTI denemesiyle açıkça görülmektedir. Bu bilgi bize yazıtın en az iki satır olduğunu belgelemektedir.

RTI metodu son yıllarda prehistorya, nümismatik, sanat tarihi ve konservasyon gibi disiplinlerde kullanılmaya başlanmıştır. Uygulamanın taşınabilirliği, düşük maliyetli olması ve eserlere zarar vermeden inceleme imkanı sunması göz önünde bulundurulduğunda kültürel miras araştırmaları kapsamında; belgeleme, koruma, arşivleme ve envanterleme çalışmalarında giderek öneminin artması kuvvetle muhtemeldir. 


\section{Fotogrametri (Photogrammetry)}

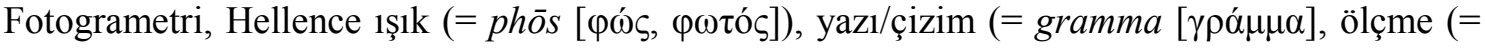
metron [ $\mu \varepsilon \dot{\tau} \tau \rho \circ])$ sözcüklerinin birleşiminden türetilmiş bir kelimedir. Işık ile çizerek ölçme anlamına gelen Fotogrametri aynı zamanda, fotoğrafların sayısallaştırılmasıyla elde edilen verilerden kesin ölçümler ve hesaplamalar yapılmasına, iki ya da daha fazla fotoğraftan üç boyutlu modeller elde edilmesine imkan veren bir bilim dalıdır. Son yıllarda söz konusu disiplinin dijital fotoğraf makineleri ve bilgisayar donanımlarındaki hızlı gelişmelerle birlikte, sub-pixel görüntü eşleştirmesi gibi sayısal algoritmalar kullanarak geliştirdiği fotogrametrik uygulamalar arkeoloji, biyoloji, konservasyon ve paleontoloji gibi birçok disiplinde kullanılmaya başlanmıştır.

Phaselis epigrafi araştırmalarında deneyimlediğimiz yakın-mesafe (close-range) fotogrametri uygulamalarından biri de Hareket Tabanlı Yapı Oluşturma (Structure from Motion -SfM-) metodudur. Bu metot birbirini takip eden farklı kamera açılarıyla çekilen fotoğrafları analiz ederek, materyalin üç boyutlu yapısını oluşturmaya olanak sağlamaktadır (Fig. 20).
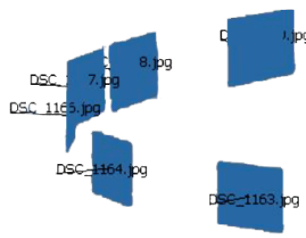
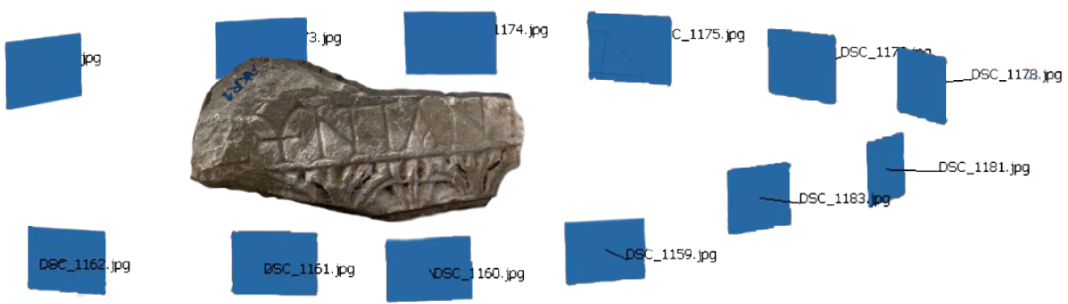

Fig. 20. Arşitrav parçasının 3 boyutlu modelin oluşturulma aşaması. Her bir kare çekilen fotoğrafin açısını göstermektedir.

$\mathrm{Bu}$ yöntem, modeli oluşturulan eserin detaylı olarak incelenmesine ve ölçümler yapılmasına imkan vermektedir. Ayrıca üzerinde çalışılan eser dijital ortamda arşivlenerek, araştırmacının tekrar araziye gitmesine gerek kalmadan çalışmalarına devam etmesine olanak sağlamaktadır.

Sonuç olarak Phaselis epigrafi çalışmalarında deneyimlenen RTI ve Fotogrametri metodlarının, maliyetlerinin uygun olması ve arazi koşullarında da uygulanabilmelerinin yanında, arazide bulunan epigrafik materyali yüksek kalitede ve üç boyutlu fotoğraflamaya olanak sağlamaktadır. Ayrıca bilgisayar ortamında detaylı analiz imkanı tanımaları bakımından, eserlerin kayıt altına alınarak belgelenmesine, arşivlenerek dijital ortamda korunmasına ve bilimsel değerelendirilmelerine önemli katkılar sundukları söylenebilir.

\section{Yazıtın Yorumlanması}

2012 araştırmaları sırasında akropolis'te, tiyatronun güneydoğusunda kireçtaşından üzeri yazıtlı arşitrav parçası bulunmuştur. Her yönden kırık olan fragman üzerinde oldukça özenli ve süslü yazılmış bir epigrafik belgeye ait altı harf korunmuştur. Yazıtın hemen alt kısmında lesbos kymation dizisi bulunur. Üçüncü ve dördüncü harf olan $\mathrm{N}$ ve P ligatür oluşturur.

Yük: $0.20 \mathrm{~m}$; gen.: $0.41 \mathrm{~m}$; der.: $0.13 \mathrm{~m}$; harf yüksekliği: 0.06 .

[-----------] $\sigma 0 ́ v \pi \alpha v \tau[\mathrm{o} / \mathrm{l}------]$

Tarih: Özenli ve süslü yazı karakteri ve bezeksel özellikleri dolayısıyla M.S. II. yüzyıl sonu III. yüzyılın ilk yarısı. 
Harflerin boyutu ve lesbos kymation dizisi yazıtın, bir yapının arşitrav’1 üzerine yazılmış ithaf yazıtına ait olabileceğini düşündürür. "Bütün, toplam, tüm" anlamlarına gelen üç bitimli $\sigma 0 ́ \mu \pi \alpha \varsigma, \bar{\alpha} \sigma \alpha, \alpha \nu$ sıfatının buradaki kullanımı için dört olasılık öne sürülebilir. Söz konusu olas1lıklara örnek vermek gerekirse: İlk olasılık accusativus casus'ta ( $\sigma 0 ́ \mu \pi \alpha v \tau \alpha)$ kullanımına yöneliktir. Aphrodisias'ta (= Geyre) ele geçen ve M.S. 361/363 y1llarına tarihlendirilen bir yazıt, yapı ile birlikte tüm süslemeleri ( Iulianus'u onurlandırır (Roueché 1989, nr. 20). İkinci olas1lık genetivus casus'ta ( $\sigma 0 ́ \mu \pi \alpha v \tau o \varsigma$ ) kullanımdır. Phaselis'te Tetragonal Agora'nın imparator Hadrianus'a ithaf edilen inşa yazıtında, imparatorun tüm evrenin kurtarıcısı olduğunu belirtmek için kullanılmıştır (TAM II 1194:

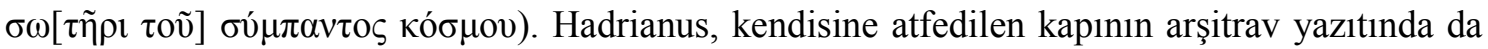
"tüm evrenin kurtarıcısı ve velinimeti" olarak adlandırılmıştır (Blackman 1981, 151 vd. nr. 1:

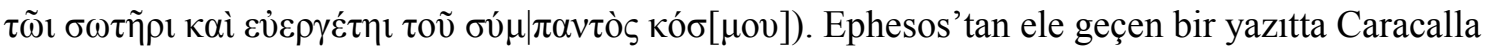

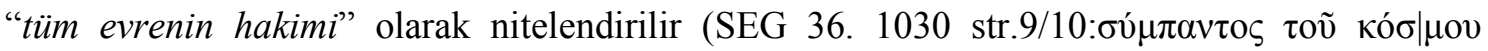
$\delta \varepsilon \sigma \pi$ ó $\eta$ ). Arykanda'da (Arif Köyü) ele geçen ve M.S. 312 y1lına tarihlenen, Lykia ve Pamphylia eyaletinin imparatorlar Maximinus, Constantinus ve Licinius'tan Hiristiyanlara ilişkin ricasını içeren dilekçenin bir edisyonunda, imparatorlar, tüm insan soyunun ve halkının

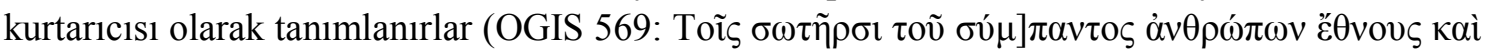

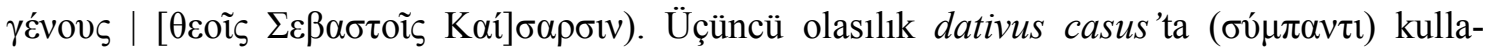
nımdır. Küçük Asya'nın pek çok kentinden ele geçen yazıtlar aracılığıyla bu casus'ta kullanımın, farklı imparatorlara ilişkin ithaf yazıtlarında, imparatorun tüm hane halkını nitelemek

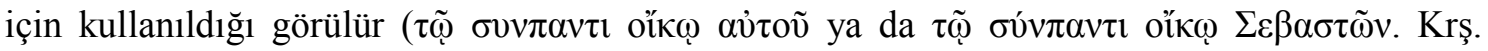
TAM III. 1/11 (Termessos: imparator Antoninus Pius için); IGR III 354 (Sagalassos: İmparator Severus Aleksander ve annesi için); SEG 14. 731 (Aphrodisias: imparator Domitianus için); SEG 28. 871 (Ephesos, imparatorlar Septimius Severus, Caracalla ve Geta için); SEG 38. 1401 (Perge, imparatorlar Septimius Severus, Caracalla ve Geta için)... etc.). Dativus casus'ta kullanım için ikinci bir olasılık vardır. Ionia kenti Metropolis’ten (Özbey Köyü) ele geçen arşitrav üzerindeki bir yazıtta geçen ve dativus casus'ta kullanılan bu sıfat [-- $\tau] \tilde{\varphi}$ $\sigma v v \pi[\alpha \nu \tau \imath$

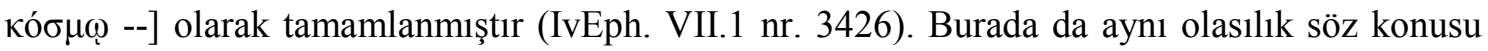

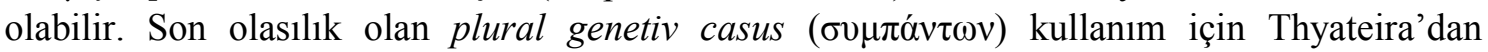
(Akhisar) ele geçen bir yazıt örnek gösterilebilir. İ.S. 14-27 arasına tarihlenen belgede kentteki

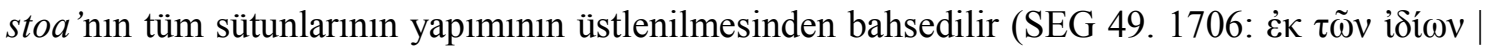

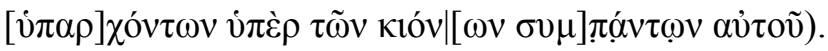

Yukarıda sayılan olasılıklardan her biri söz konusu yazıt için geçerli olabilir. Bu konuya açıklık getirilebilmesi ancak akropolis'te sürdürülecek çalışmalarda söz konusu yazıta ilişkin yeni fragmanlar bulunmasına bağlıdır. 


\section{KAYNAKÇA}

Blackman, D. J. (1981). "The Inscriptions”. In, Phaselis. Beiträge zur Topographie und Geschichte der Stadt und ihrer Häfen. Ed. J. Schäfer. Tübingen, 138-163.

IvEph. Die Inschriften von Ephesos, VII/1, IK 17.1 Eds. R. Meriç - R. Merkelbach - J. Nollé. Bonn 1981.

Malzbender, T., Gelb, D., \& Wolters, H. (2001) "Polynomial Texture Maps". Proceedings of the $28^{\text {th }}$ Annual Conference on Computer Graphics and Interactive Techniques. Los Angeles, California, 519-528.

Mudge, M., Malzbender, T., Schroer, C., \& Marlin, L. (2006). "New Reflection Transformation Imaging Methods for Rock Art and Multiple-Viewpoint Display”. Eds. M. Ioannides, D. Arnold, F. Niccolucci, \& K. Mania, The $7^{\text {th }}$ International Symposium on Virtual Reality, Archaeology and Cultural Heritage VAST, (2006).

OGIS, Orientis Graeci Inscriptiones Selectae.

Roueché, C. (with contributions by J. M. Reynolds) (1989). Aphrodisias in Late Antiquity. The Late Roman and Byzantine Inscriptions including Texts from the Excavations at Aphrodisias Conducted by Kenan T. Erim. Journal of Roman Studies Monograph 5, London: Society for the Promotion of Roman Studies.

Schäfer, J. (1981). Phaselis. Beiträge zur Topographie und Geschichte der Stadt und ihrer Häfen. Ist. Mitt. Beiheft 24, Tübingen 1981.

SEG, Supplementum Epigraphicum Graecum.

TAM, Tutili Asia Minoris.

Tüner, Önen, N. (2008). Phaselis Antik Kenti ve Teritoryumu. Akdeniz Üniversitesi, Sosyal Bilimler Enstitüsü, Yayınlanmamış Doktora Tezi. Antalya.

Ümit, O. (1996). Phaselis Tarihsel Su Iletimi. Pamukkale Üniversitesi Mühendislik Fakültesi İnşaat Mühendisliği Bölümü Hidrolik Anabilim Dalı Su Kaynakları Bilim Dalı Diploma Çalışması No. 27, Denizli 1996. 